\title{
Analisis SWOT Pada Layanan Jasa Mobile Banking Di PT Bank Panin Dubai Syariah
}

\author{
Muhammad Ryzki Wiryawan', Cici Amalia Hidayati Sulaiman² \\ ${ }^{1}$ Fakultas Komputer, Ma'soem University \\ ${ }^{2}$ Fakultas Ekonomi dan Bisnis Islam, STIBANKS Al Masoem \\ Email: ryzki.wiryawan@gmail.com, ciciamalia20@gmail.com
}

\begin{abstract}
ABSTRAK
Dalam beberapa tahun terakhir, Bank telah menyesuaikan layanan perbankannya, dari yang sebelumnya berbasis kertas menjadi berbasis seluler atau mobile. Adopsi Mobile-banking telah mendapat perhatian lebih dalam beberapa tahun terakhir, karena memang ada lebih banyak telepon daripada komputer di pasaran. Di Indonesia, satu per satu bank mulai mengadopsi teknologi tersebut untuk bisa bersaing, salah satunya Bank Panin Dubai Syariah yang memulainya pada 2019. Penelitian ini mencoba menganalisis layanan jasa mobile banking di PT Bank Panin Dubai Syariah menggunakan pendekatan SWOT. Penelitian ini menggunakan metode kualitatif deskriptif, Menggunakan teknik pengumpulan data berupa observasi, wawancara, dokumentasi, dan studi pustaka. Studi menunjukan bahwa berdasarkan diagram cartesius, layanan Mobile Banking Bank Panin Dubai Syariah berada pada kuadran I (satu) yaitu mendukung growth oriented strategy (strategi agresif).
\end{abstract}

Kata Kunci: Mobile Banking, SWOT, Bank Syariah

\begin{abstract}
In recent years, Banks has adjusted its banking services, from previously paperbased to mobile-based. Mobile banking technology adoption has received more attention in recent years, as there are indeed more phones than computers on the market. In Indonesia, more banks are starting to adopt this technology to be able to compete, one of which is the Panin Dubai Syariah Bank which started in 2019. This study tries to analyze mobile banking services at PT Bank Panin Dubai Syariah using the SWOT approach. This study uses descriptive qualitative methods, using data collection techniques in the form of observation, interviews, documentation, and literature study. The study shows that based on the Cartesian diagram, the Panin Dubai Syariah Bank Mobile Banking service was placed in quadrant I (one), which is to support a growth-oriented strategy.
\end{abstract}

Keywords: Mobile Banking, SWOT, Islamic Bank

\section{PENDAHULUAN}

\section{Latar Belakang Masalah}

Dalam beberapa tahun terakhir, mobile banking, e-commerce, dan sistem lainnya telah mengalami perkembangan pesat dan peningkatan penggunanya. Di saat 
bersamaan, masyarakat mengalami pergeseran transformatif dari ekonomi berbasis uang tunai menjadi ekonomi yang menggunakan pembayaran elektronik seluler. Penelitian terbaru menunjukkan bahwa perbankan ikut memanfaatkan teknologi terbaru ini dalam upaya meningkatkan kepuasan nasabah dan menurunkan biaya operasional bank ((Chirani, I., \& Ghofrani, 2010; Kim, Y. J., Chun, J. U., \& Song, n.d.). Mobile banking semakin berkembang ketika lembaga keuangan (terutama bank) mulai menyadari bahwa pendekatan baru ini memberikan banyak keuntungan bagi mereka, seperti memungkinkan layanan bank untuk bebas dari batasan wilayah geografis tertentu, sehingga mereka bisa beroperasi di pasar baru, meningkatkan kinerja, meningkatkan loyalitas pelanggan, dan mengurangi biaya operasional dan lainnya. Selain itu, pelanggan mendapatkan keuntungan dari layanan yang disesuaikan dan dipersonalisasi serta pengurangan waktu tunggu demi layanan yang lebih nyaman (Cheng, D., Liu, G., \& Qian, 2008; Cheung, C. M., \& Lee, 2005). Gambaran pengguna mobile banking di Indonesia adalah sebagai berikut:

Tabel 1. Jumlah Pengguna Mobile Banking pada Bank Umum Syariah

\begin{tabular}{|c|c|c|}
\hline Nama Bank & Nama Mobile Banking & Jumlah \\
\hline $\begin{array}{l}\text { 1. PT. Bank } \\
\text { Muamalat } \\
\text { Indonesia }\end{array}$ & Muamalat Mobile & $\begin{array}{c}500.000 \\
\text { Orang }\end{array}$ \\
\hline $\begin{array}{l}\text { 2. PT. Bank Syariah } \\
\text { Mandiri }\end{array}$ & Mandiri Syariah Mobile & $\begin{array}{l}1.000 .000 \\
\text { Orang }\end{array}$ \\
\hline $\begin{array}{l}\text { 3. PT. Bank Mega } \\
\text { Syariah }\end{array}$ & Mega Syariah Mobile & 10.000 Orang \\
\hline $\begin{array}{l}\text { 4. PT. Bank BRI } \\
\text { Syariah }\end{array}$ & BRIS Online & $\begin{array}{c}500.000 \\
\text { Orang }\end{array}$ \\
\hline $\begin{array}{l}\text { 5. PT. Bank Syariah } \\
\text { Bukopin }\end{array}$ & BSB Mobile Banking & 5.000 Orang \\
\hline $\begin{array}{l}\text { 6. PT. Bank BNI } \\
\text { Syariah } \\
\end{array}$ & BNI Mobile Banking & $\begin{array}{c}5.000 .000 \\
\text { Orang }\end{array}$ \\
\hline $\begin{array}{l}\text { 7. PT. Bank Jabar } \\
\text { Banten Syariah }\end{array}$ & Mobile Maslahah & 10.000 Orang \\
\hline 8. PT. BCA Syariah & BCA Syariah Mobile & 50.000 Orang \\
\hline $\begin{array}{l}\text { 9. PT. Bank Panin } \\
\text { Dubai Syariah }\end{array}$ & Panin Dubai Mobile & 1.000 Orang \\
\hline 10. PT. BTPN Syariah & BTPN Syariah Mobile & 5.000 Orang \\
\hline
\end{tabular}

Berdasarkan data di atas, terlihat bahwa saat ini hampir seluruh bank-bank besar di Indonesia menyediakan akses mobile banking untuk memudahkan nasabah dalam mengakses layanan perbankannya. PT Bank Panin Dubai Syariah adalah satu bank yang mengadopsi teknologi mobile banking bagi para nasabahnya. Produk mobile 
banking PT Bank Panin Dubai Syariah yang bernama PDSB Mobile diluncurkan pada tahun 2019 dan menjadi salah satu tombak perbankan untuk memajukan bisnisnya sesuai dengan kebutuhan nasabah, apalagi porsi pengguna PDSB mobile masih relatif sedikit dibandingkan dengan bank Syariah lainnya. Data di atas juga menunjukan bahwa porsi pengguna mobile banking bank syariah masih rendah dibandingkan penduduk Indonesia. Salah satu penyebabnya adalah akses yang tidak merata terhadap layanan perbankan yang masih dihadapi oleh lembaga perbankan, terutama di daerah terpencil yang tidak terjangkau oleh lembaga perbankan dan jasa keuangan, karena kondisi masyarakat yang belum sepenuhnya mengenal layanan perbankan dan jasa keuangan lainnya. sehingga berpotensi dimanfaatkan oleh pihak yang tidak bertanggung jawab (Habibi, 2016).

Pengembangan PDSB mobile salah satunya bisa diketahui lewat analisis SWOT. Analisis SWOT adalah identifikasi berbagai faktor secara sistematis untuk merumuskan strategi perusahaan. Analisis ini didasarkan pada logika yang dapat memaksimalkan kekuatan (strength) dan peluang (opportunities), namun secara bersamaan dapat meminimalkan kelemahan (weakneses) dan ancaman (threats). Proses pengambilan keputusan harus berkaitan dengan visi, misi, tujuan, strategi serta kebijakan perusahaan (Rangkuti, 2016).

Terdapat beberapa penelitian sebelumnya yang telah membahas tema mobile banking dalam berbagai pendekatan. Rema, Y.\& Setyohadi (2016) menyelidiki niat penggunaan kembali mobile banking oleh nasabah Bank BRI Cabang Bajawa mengadaptasi teori Unified Theori of Acceptance and Use of Technology (UTAUT) yang dimodifikasi dengan tambahan dua variabel yaitu Perceived Security dan Perceived Financial Cost yang merupakan variabel yang diadaptasi dari perceived risk. Hasil penelitian menunjukan persepsi keamanan dan kemudahan penggunaan menjadi faktor yang paling menentukan dalam niat perilaku seseorang untuk menggunakan mobile banking (Rema, Y.\& Setyohadi, 2016). Ronny (2017) melakukan penelitian terkait kekuatan apa yang menjadi landasan layanan jasa di bidang internet banking. Penelitian dilakukan dengan menganalisis persepsi nasabah pada 5 variabel kualitas layanan yakni keamanan, keandalan, responsif, kemampuan fisik, dan jaminan. Hasil analisis menunjukkan bahwa terdapat 6 kekuatan yang melandasi kualitas layanan jasa internet banking yakni komunikasi, 
saluran partisipasi nasabah, fasilitas layanan, sumber daya manusia, infrastruktur teknologi dan norma. Keenam kekuatan layanan internet banking tersebut merupakan dimensi kekuatan bersaing dalam industri. Penggunaan SWOT untuk menganalisis mobile banking telah dilakukan Hafiz (2018) dalam skripsinya di Universitas Islam Negeri Syarif Hidayatullah Jakarta yang berjudul "Analisis SWOT Layanan Mobile Banking pada Bank Syariah Mandiri Kantor Cabang Pondok Indah". Penelitiannya menunjukan bahwa terdapat pengaruh strategi secara signifikan antara layanan mobile banking dengan sistem penunjang transaksi perbankan Syariah di Indonesia. Penelitian lain dilakukan oleh Ningrum (2019), yang menunjukan bahwa pada umumnya kekuatan mobile banking berada pada: Meminimalisir layanan biaya operasional pegadaian Syariah, Layanan transaksi dapat dilakukan dimana saja, dan layanan informasi yang cepat. Adapun kelemahannya yaitu: kurangnya perlindungan hak privasi, serta ketergantungan pada jaringan dan internet. Peluang mobile banking antara lain: Adanya penerapan teknologi-teknologi baru dengan perkembangan IT dan potensi umat Islam sebagai nasabah bank Syariah. Kemudian ancaman mobile banking yaitu: penyesuaian pada teknologi yang lebih canggih dari pesaing dan terjadinya cyber crime.

Berdasarkan uraian diatas, disimpulkan bahwa pengembangan mobile banking dalam perbankan syariah perlu dilakukan untuk meningkatkan peminat bank Syariah dibandingkan bank konvensional, dan untuk bisa mewujudkannya, maka perlu dilakukan analisis SWOT untuk mengetahui berbagai kekuatan dan kelemahan yang dimiliki, ancaman yang dihadapi baik internal maupun eksternal dan meraih peluang yang ada. Maka dari itu penulis dalam penelitian ini membawa judul "Analisis SWOT pada Layanan Jasa Mobile Banking di PT Bank Panin Dubai Syariah".

\section{Identifikasi Masalah}

Berdasarkan latar belakang di atas, dapat diuraikan identifikasi masalah sebagai berikut :

1. Bagaimana analisis kekuatan (strenghs) layanan mobile banking PT Bank Panin Dubai Syariah?

2. Bagaimana analisis kelemahan (weaknesses) layanan mobile banking PT Bank Panin Dubai Syariah? 
3. Bagaimana analisis peluang (opportunities) layanan mobile banking PT Bank Panin Dubai Syariah?

4. Bagaimana analisis ancaman (threats) layanan mobile banking PT Bank Panin Dubai Syariah ?

5. Bagaimana analisis matriks SWOT layanan mobile banking PT Bank Panin Dubai Syariah?

\section{Ruang Lingkup dan Pembatasan Masalah}

Ruang lingkup yang akan dibahas dalam penelitian ini adalah produk jasa mobile banking yang dimiliki oleh PT Bank Panin Dubai Syariah dalam konteks analisis SWOT.

\section{Tujuan Penelitian}

Adapun tujuan penelitian ini diharapkan dapat menjadi rekomendasi bagi manajemen perbankan syariah, khususnya PT Bank Panin Dubai Syariah untuk meningkatkan kualitas layanan atau pengguna layanan perbankan syariah di seluruh Indonesia melalui penerapan teknologi keuangan terkini.

\section{TINJAUAN TEORITIS}

\section{Definisi Bank Syariah}

Undang-Undang Nomor 21 Tahun 2008 menyebutkan bahwa : "Perbankan Syariah adalah segala sesuatu yang menyangkut Bank Syariah dan Unit Usaha Syariah, mencakup kelembagaan, kegiatan usaha, serta cara dan proses dalam melaksanakan kegiatan usahanya".

Bank Syariah adalah bank yang melaksanakan kegiatan operasionalnya terkait dengan pengumpulan dana atau penyaluran dana serta memberikan dan mengenakan imbalan terhadap suatu jasa sesuai dasar prinsip Syariah (Karim, 2003; Usman, n.d.; Wibowo, Edy, 2005). Prinsip dasar perbankan syariah berdasarkan pada alQuran dan sunnah. Setelah dikaji lebih dalam Falsafah dasar beroperasinya bank syariah yang menjiwai seluruh hubungan transaksinya berprinsip pada tiga hal yaitu efisiensi, keadilan, dan kebersamaan (Wibowo, Edy, 2005). 
PT Bank Panin Dubai Syariah Tbk atau Panin Dubai Syariah Bank (Perseroan) berdiri diatas Akta Perseroan Bank Terbatas No. 12 tanggal 8 Januari 1972 yang dibuat oleh seorang Notaris di Malang bernama Moeslim Dalid dengan nama awal PT Bank Pasar Bersaudara Djaja. Perubahan nama telah dilakukan oleh perseroan ini secara berulang kali. Diawali dengan nama PT Bank Bersaudara Djaja pada 1990, menjadi PT Bank Harfa pada 1997, menjadi PT Bank Panin Syariah pada 2009, menjadi PT Bank Panin Syariah Tbk pada 2013 dan akhirnya menjadi PT Bank Panin Dubai Syariah Tbk terkait dengan adanya pemasukan saham dari Dubai Islamic Bank PJSC sebagai salah satu Pemegang Saham pada 2016, PT Bank Panin Dubai Syariah berkantor pusat di Gedung Panin Life Center Lantai $3 \mathrm{Jl}$. Letjend S. Parman Kav. 9 Jakarta Barat 11420 dan untuk terus mengembangkan usahanya PT Bank Panin Dubai Syariah mendirikan beberapa kantor cabang yang terdapat di 16 lokasi.

\section{Definisi Analisis SWOT}

Analisis SWOT adalah alat yang umum digunakan untuk memfasilitasi tinjauan strategis suatu organisasi. Melakukan analisis menggunakan SWOT membantu untuk memfokuskan kegiatan ke area di mana kekuatan dan peluang terbesar berada. Pengetahuan ini kemudian digunakan untuk mengembangkan rencana tindakan. Analisis dapat dilakukan pada suatu produk, pada layanan, perusahaan, atau bahkan pada individu. SWOT dalam bahasa Indonesia dijabarkan sebagai kekuatan, kelemahan, peluang, dan ancaman. Kekuatan dan kelemahan bersifat faktor internal. Sedangkan peluang dan ancaman bersifat faktor eksternal. Tujuan dari Analisis SWOT adalah mengumpulkan, menganalisis, dan mengevaluasi informasi dan mengidentifikasi pilihan strategis yang dihadapi komunitas, organisasi, atau individu pada suatu waktu waktu (Glaister, K. W., \& Falshaw, 1999; Hung, 2013; Kotler, P., 2008).

Rangkuti (2016) menyebutkan bahwa dalam melakukan proses analisis menggunakan metode analisis SWOT yang disusun dalam kerangka sebagai berikut: 


\begin{tabular}{|c|}
\hline $\begin{array}{c}\text { 1. TAHAP PENGUMPULAN DATA } \\
\text { a. Evaluasi Faktor Ekternal } \\
\text { b. Evaluasi Faktor Internal }\end{array}$ \\
2. TAHAP ANALISIS \\
Matriks SWOT \\
\hline 3. TAHAP PENGAMBILAN KEPUTUSAN \\
Matriks Perencanaan Strategis Kuantitatif
\end{tabular}

Gambar 1: Kerangka Formulasi Strategis

Sumber :Rangkuti (2016: 23)

\section{Mobile Banking}

Ikatan Bankir Indonesia (2014) menyebutkan bahwa Mobile Banking merupakan suatu bentuk dari layanan jasa yang tersedia pada beberapa dunia perbankan yang dapat digunakan oleh nasabah lewat pemanfaatan telepon seluler (Handphone)/ telepon seluler GSM (Global for Mobile Communication) melalui Short Message Service (SMS). Beberapa bentuk transaksi yang bisa digunakan dalam Mobile Banking antara lain:

a. Transfer uang

b. Mengecek informasi saldo dan informasi nilai tukar

c. Melakukan mutasi rekening

d. Nasabah dapat melakukan pembayaran tagihan seperti pembayaran pada kartu kredit, PLN, handphone, listrik, dan asuransi

e. Pembelian yang dapat dilakukan oleh nasabah seperti pulsa isi ulang dan saham.

Berdasarkan asosiasi perbankan Pakistan, mobile banking tampaknya secara bertahap menggantikan layanan perbankan berbasis kertas alih-alih melengkapinya (Abbas, S. K., Hassan, H. A., Asif, J., Junaid, H. M., \& Zainab, 2018). Di negara berkembang, proporsi pengguna mobile banking melalui perangkat seluler, telah meningkat dari 25 menjadi 37 persen dalam survei terakhir. Sebagian besar penggunanya berusia muda (45 persen berusia 18 hingga 29 tahun) (Silver, L., Smith, A., Johnson, C., Taylor, K., Jiang, J., Anderson, M., \& Rainie, 2019).

Menurut penelitian terbaru, nasabah mobile banking di satu sisi lebih loyal, tetapi di sisi lain mereka juga lebih terbuka untuk tawaran dari bank mereka sendiri. Oleh karena itu, lembaga keuangan harus berinvestasi lebih jauh dalam 
pengembangan penawaran digital mereka (Abbas, S. K., Hassan, H. A., Iftikhar, S., \& Waris, 2018).

\section{METODOLOGI}

\section{Metode Penelitian}

Objek penelitian pada skripsi ini adalah layanan jasa mobile banking pada PT Bank Panin Dubai Syariah KCU Bandung dengan menggunakan metode analisis SWOT. Metode penelitian yang digunakan pada skripsi ini adalah metode deskriptif kualitatif. Sugiyono (2018) mengatakan bahwa metode penelitian kualitatif ialah metode penelitian yang berlandaskan pada filsafat positivisme digunakan untuk meneliti pada kondisi obyek yang alamiah, dimana peneliti adalah sebagai instrumen kunci, teknik pengumpulan data dilakukan secara triangulasi (gabungan), analisis data bersifat induktif/kualitatif, dan hasil penelitian kualitatif lebih menekankan makna daripada generalisasi. Sementara Moleong (2005) menyebutkan bahwa penelitian kualitatif adalah sebuah metode yang dilakukan dalam penelitian yang bertujuan untuk memberi pemahaman terkait fenomena yang terjadi dan dialami oleh subjek penelitian seperti tindakan, motivasi, persepsi, perilaku secara holistik dan dengan penjelasan atau penjabaran dalam bentuk kata atau bahasa yang ada dalam suatu konteks khusus yang bersifat alamiah dan memanfaatkan metode alamiah. Lebih lanjut, Mukhtar (2013) menyatakan bahwa penelitian deskriptif adalah salah satu metode yang digunakan oleh subjek penelitian dengan tujuan untuk menemukan wawasan, teori atau pengetahuan atas penelitian dalam satu kurun waktu tertentu. Penggunaan metode penelitian deskriptif kualitatif bertujuan untuk menggambarkan, meringkas, berbagai kondisi, situasi, atau fenomena realitas sosial yang ada di masyarakat yang menjadi objek penelitian (Bungin \& Burhan, 2008).

Teknik analisis data kualitatif yang dilakukan penulis yaitu : Pengumpulan Data, Reduksi Data, Penyajian Data, dan Kesimpulan (Conclusion Drawing).

Data yang digunakan penelitian ini terdiri dari data primer yaitu hasil wawancara secara langsung dan penyebaran angket terhadap pihak yang berkaitan dengan layanan jasa mobile banking pada PT Bank Panin Dubai Syariah. Adapun data 
sekuder dalam penelitian ini bersumber dari studi pustaka dan dokumen resmi yang diperoleh dari pihak PT Bank Panin Dubai Syariah KCU Bandung.

Dalam penelitian ini peneliti menggunakan teknik non probability sampling, dengan populasi seluruh pihak yang terlibat dengan layanan jasa mobile banking di PT Bank Panin Dubai Syariah. Sedangkan sampel pada skripsi ini adalah informan kebijakan SWOT (pengelola mobile banking) di PT Bank Panin Dubai Syariah KCU Bandung dan nasabah mobile banking di PT Bank Panin Dubai Syariah.

\section{Narasumber}

Wawancara dan penyebaran angket dilakukan terhadap pihak Bank yang paling mengetahui perihal pelaksanaan pelayanan PDSB mobile, dalam hal ini diwakili oleh pihak PT Bank Panin Dubai Syariah KCU Bandung : Bpk. RF (Bagian Back Office), Sdr. TN. dan RKB (Bagian Customer Service), serta Sdr. AD sebagai perwakilan nasabah.

\section{PEMBAHASAN}

Berikut adalah analisis strengths, weaknesses, opportunities dan threats (SWOT) pada layanan jasa mobile banking PT. Bank Panin Dubai Syariah. Selain itu, data yang diperoleh dan disajikan dalam bentuk angka, hasil penelitian atau hasil dari pelaksanaan wawancara.

\section{Strengths}

Adapun strengths atau kekuatan yang dimiliki dan perlu dikembangkan oleh PT Bank Panin Dubai Syariah dalam meningkatkan layanan jasa mobile banking yaitu sebagai berikut :

1. Meminimalisir biaya operasional pada bank

Meminimalisir biaya operasional adalah salah satu bentuk kegiatan yang dilakukan setiap bidang usaha baik keuangan atau non keuangan demi memperoleh keuntungan dan menekan biaya operasional. Pihak PT Bank Panin Dubai Syariah berhasil menekan biaya operasional melalui pemanfaatan mobile banking. Sebagaimana diungkapkan oleh Bapak RF, kekuatan dalam pemasaran dapat dikuatkan dengan menekan biaya operasional melalui pemanfaatan teknologi. Hal ini sejalan dengan penelitian Hafiz (2018), bahwa 
keberadaan mobile banking dapat memberi keuntungan salah satunya adalah meminimalisir biaya operasional dan dapat memaksimalkan pemberian layanan kepada nasabah, serta pihak bank mampu memblokir rekening yang disalahgunakan oleh nasabah.

2. Citra PT. Bank Panin Dubai Syariah yang baik.

Citra perusahaan dibutuhkan dalam peningkatan kualitas pada suatu produk. Berdasarkan hasil wawancara dengan Sdr. RK, layanan mobile banking menjadi salah pendorong pihak bank Panin Dubai Syariah untuk menunjukkan eksistensinya dalam dunia perbankan syariah.

3. Fitur yang tersedia di PDSB Mobile sesuai dengan ajaran Islam dan memberikan kemudahan serta kenyamanan bagi nasabah.

Prinsip ekonomi Islam mendorong penganutnya untuk mendapatkan dan memberikan rahmat kepada seluruh alam (rahmatan lil 'aalamiin), salah satunya adalah mendorong kemajuan teknologi yang dapat mendekatkan diri kepada Allah SWT (Darussalam, A. Z. and Malik, 2017; Tutuko, B., Hudaifah, A. and Zulfikar, 2017), dengan demikian mobile banking memiliki peran penting. Selain itu, nasabah mengakui bahwa mobile banking dapat menyelesaikan transaksi secara efektif dan efesien tanpa membuang banyak waktu dan tenaga. Fitur yang menjadi favorit nasabah adalah pengecekan saldo sehingga nasabah dapat melihat jumlah dana yang dimiliki dalam rekening melalui telepon seluler.

4. Relasi antara pihak bank dan nasabah pengguna PDSB Mobile Sejalan dengan penelitian Abbas, S. K., Hassan, H. A., Asif, J., Junaid, H. M., \& Zainab, (2018), nasabah mobile banking di satu sisi lebih loyal, tetapi di sisi lain mereka juga lebih terbuka untuk tawaran dari bank mereka sendiri. Dalam melaksanakan kerjasama yang baik antara pihak bank dan nasabah diperlukan relasi atau hubungan yang baik agar terciptanya rasa loyalitas nasabah terhadap penggunaan mobile banking.

5. Tingkat kepercayaan nasabah dalam menggunakan PDSB Mobile Pavlou (2001) menyebutkan bahwa faktor kepercayaan dari binis berbasis elektronik yaitu perkiraan secara subyektif berasal dari konsumen yang percaya bahwa transaksi dapat dilakukan secara online dengan konsisten dan lebih 
sempurna sesuai dengan kebutuhan. Konsep kepercayaan yang dibangun disini adalah peningkatan rasa percaya dari pihak bank dan pihak nasabah untuk melakukan transaksi online dalam mobile banking.

\section{Weaknesses}

Adapun weaknesses atau kelemahan harus diminimalisir oleh PT Bank Panin Dubai Syariah dalam meningkatkan layanan jasa mobile banking yaitu sebagai berikut :

1. Ketergantungan pada jaringan internet dan Service SMS/SIM Tool

Salah satu kelemahan dari PDSB Mobile adalah ketergantungan pada jaringan internet dan berjalan diatas service SMS dan SIM Tool. Hal ini dilihat dari nomor telepon seluler yang digunakan nasabah ketika akan membuka rekening. Dan berdasarkan informasi dari narasumber Sdr. TN mengatakan bahwa nomor telepon seluler yang digunakan adalah nomor telepon yang aktif dan tidak dapat diakses oleh orang lain kecuali atas kuasa dari pemilik akun. Selain itu, jika nasabah tidak memiliki kuota internet maka tidak dapat mengakses PDSB Mobile. Tidak hanya itu, jika pada saat pelaksanaan transaksi internet mengalami gangguan atau yang lebih dikenal dengan server error maka transaksi yang sedang dilakukan gagal.

2. Keamanan data nasabah pada PDSB Mobile

Keamanan data nasabah adalah hal utama yang menjadi pusat perhatian bank. Berdasarkan hasil wawancara, narasumber Sdr TN menyatakan bahwa untuk menjaga keamanan data nasabah pihak bank telah mengaktifkan akun rekening dengan menggunakan keamanan security end-to-end dan dapat meminimalisir angka pembobolan rekening oleh pihak yang tidak bertanggung jawab. Selain itu, Bapak RF menyatakan bahwa OJK dan Bank Indonesia serta diawasi oleh Dewan Pengawas Syariah telah menyusun dan membentuk peraturan terkait keamanan data nasabah. Akan tetapi, hal ini tidak menutup kemungkinan jika ada pihak yang tidak bertanggungjawab lebih mudah menyerang nasabah dengan sistem penipuan atau yang lebih dikenal dengan smishing. Dimana pihak tertentu mengaku dirinya sebagai intuisi keuangan lalu menanyakan detail rekening dan akun dari mobile banking tersebut. Sehingga bank 
mengingatkan kepada para nasabahnya untuk lebih berhati-hati dalam penggunaan mobile banking.

3. Pemasaran PDSB Mobile kepada nasabah

Pemasaran adalaah salah satu bentuk kegiatan bisnis yang mendapatkan perhatian khusus guna mencapai target dari sebuah perusahaan. Pemasaran mobile banking kepada nasabah di PT Bank Panin Dubai Syariah sampai saat ini dilakukan melalui informasi mulut ke mulut (Word of Mouth) dan titik fokus utama pihak bank adalah nasabah prioritas. Kelemahan dari cara ini adalah tidak menutup kemungkinan adanya kesalahan dalam penyampain informasi (miscommunication).

4. Aksesibilitas

Penyediaan layanan jasa mobile banking masih terdapat kekurangan seperti disampaikan oleh Bapak RF yaitu tidak adanya virtual account dan tidak dapat diakses oleh pengguna android versi 10 dan i-phone.

5. Target jumlah nasabah.

Dalam mencapai kesuksesan sebuah perusahaan harus memiliki target atau pencapaian dalam melakukan kegiatan bisnis. Tapi narasumber menyatakan bahwa pihak bank tidak membuat target nasabah dalam daftar pencapaian bisnisnya dikarenakan sistem operasional PDSB Mobile yang terbilang baru. PDSB Mobile muncul di PT Bank Panin Dubai Syariah KCU Bandung sejak 21 November 2019.

\section{Opportunities}

Adapun opportunities atau peluang yang dihadapi dan harus diketahui oleh PT Bank Panin Dubai Syariah KCU Bandung dalam meningkatkan layanan jasa mobile banking yaitu sebagai berikut :

1. Pengguna PDSB Mobile dominan adalah beragama Islam

Herawati \& Listyawati (2017) mengatakan bahwa masyarakat muslim lebih memilih bank syariah karena pengetahuannya terhadap bidang ekonomi syariah, pengalaman yang didapat dari rekan sesamanya yang menggunakan bank dan layanan jasa yang sama, dan lokasi bank syariah yang strategis. Dengan jumlah umat Islam di Indonesia yang mencapai 90\% dari populasi, 
tentunya masih terbuka banyak peluang untuk menarik peminat dari kalangan tersebut.

2. Perkembangan fitur pada PDSB Mobile diiringi dengan perkembangan IT Kadir (2003) menyatakan bahwa peranan teknologi informasi antara lain memudahkan pekerjaan manusia, memberi kekuatan pada manusia dalam melakukan penyajian data, dan dapat memberikan perubahan dengan sistem yang efesien dan efektif. Seperti yang dikatakan oleh narasumber Sdr. RK bahwa perbaikan fitur semisalnya pengadaan virtual account, kemudahan akses login untuk android versi 10 dan i-phone pada PDSB Mobile dapat meningkatkan jumlah nasabah. Sehingga hal ini yang membawa PT Bank Panin Dubai Syariah KCU Bandung untuk berinovasi dan meningkatkan kreativitas dalam penyediaan layanan jasa mobile banking berbasis syariah dengan mengikuti teknologi informasi.

3. Peraturan dan perizinan dari pemerintah atas operasional PDSB Mobile Dalam melaksanakan kegiatan operasionalnya, PT Bank Panin Dubai Syariah KCU Bandung tidak terlepas dari perizinan yang berasal dari pemerintah. Dengan demikian meningkatkan kepercayaan nasabah dalam penggunaan PDSB Mobile

\section{Kemampuan Customer Service}

Kinerja seorang karyawan menjadi tolak ukur dalam memperoleh keputusan dan kepercayaan nasabah dalam menggunakan mobile banking. Hal ini dibenarkan oleh Herawati \& Listyawati (2017) bahwa peningkatkan jumlah nasabah di bank syariah dapat dilihat dari tingkat kemampuan customer service atau karyawan lainnya dalam memasarkan produk dengan ramah, sopan dan tanggap. Sistem pemasaran yang dilakukan oleh pihak bank dengan sistem mulut ke mulut (word of mouth) menjadi tolak ukur dari kemampuan karyawan khususnya customer service.

5. Relasi Antara Kantor Pusat Dan Kantor Cabang.

Relasi atau jaringan adalah sebuah strategi bisnis untuk memperluas wilayah pemasaran. Relasi yang menjadi daya kekuatan PDSB Mobile ditegaskan oleh narasumber Sdr. TN bahwa pihak kantor cabang hanya menjadi agen dalam layanan jasa dan perbaikan sistem/server sementara. Sedangkan pihak pusat 
adalah pihak yang berkuasa penuh dengan adanya pengembangan atau perbaikan sistem pada PDSB Mobile serta menjadi server utama. Sehingga dalam hal ini menjaga hubungan baik dengan kantor pusat adalah faktor utama dalam membangun dan meningkatkan kualitas PDSB Mobile ke arah yang lebih baik lagi dengan segala inovasi dan kreativitas.

\section{Threats}

Adapun threats atau ancaman yang dihadapi dan harus dihindari oleh PT Bank Panin Dubai Syariah dalam meningkatkan layanan jasa mobile banking yaitu sebagai berikut :

1. Kemampuan Bank Untuk Membaca Persaingan Pasar Mobile Banking Salah satu cara perbankan untuk dapat bersaing ditengah institusi perbankan lainnya yaitu dengan menyempurnakan atau memperbaiki fitur pada produk atau layanan yang tersedia. Hal ini menjadi perhatian khusus bagi PT Bank Panin Dubai Syariah KCU Bandung dalam melakukan pemasaran PDSB Mobile guna meningkatkan kualitas dan kuantitas dari pengunaan mobile banking.

\section{Perkembangan Segmentasi Pasar M-Banking}

Menurut Kotler, P. (2008) segmentasi pasar adalah pengelompokan pasar menjadi beberapa bagian pembeli yang memiliki klasifikasi yang berbeda berdasarkan tujuannya untuk dapat mengubah bentuk pasar yang heterogen kemudian berubah menjadi homogen. Bapak RF mengatakan bahwa salah satu ancaman PDSB Mobile adalah segmentasi pasar dikarenakan PT Bank Panin Dubai Syariah baru saja meluncurkan mobile banking, tidak semua golongan usia familiar dengan fitur tersebut.

3. Tingkat Penawaran Dan Kebutuhan Nasabah

Penawaran ialah total dari keseluruhan barang yang dimiliki oleh produsen untuk dipasarkan kepada pembeli pada level harga dan waktu tertentu. Tingkat penawaran ini dapat dirasakan oleh PT Bank Panin Dubai Syariah KCU Bandung dan berasal dari banyak faktor diantaranya adalah kemajuan teknologi informasi dan biaya operasional yang telah dijelaskan sebelumnya. 
Menurut narasumber bapak RF, kebutuhan pengguna PDSB Mobile yang beragam menjadi faktor ancaman dalam tingkat penawaran.

4. Pengembangan Pelayanan PDSB Mobile oleh Kantor Pusat Pelayanan yang dibangun oleh pihak bank bertujuan untuk mencapai pelayanan prima (excellent service). Narasumber Sdr. TN mengatakan bahwa kantor pusat adalah pusat utama atau server dalam perbaikan PDSB Mobile. Hal ini menjadi poin penting bagi pihak PT Bank Panin Dubai Syariah KCU Bandung untuk tetap membangun kerjasama yang baik dengan kantor pusat agar dapat mengembangakan PDSB Mobile sesuai dengan kebutuhan nasabah.

5. Pengembangan Kemampuan Manajerial

Kemampuan manajerial dalam pengembangan PDSB Mobile adalah hal utama yang menjadi faktor pendorong bagi PT Bank Panin Dubai Syariah KCU Bandung untuk terus berkembang, berinovasi dan berkreativitas. Seperti yang diungkapkan oleh narasumber bahwa sistem manajemen yang berada pada PDSB Mobile masih sangat kurang dikarenakan PDSB Mobile yang baru diluncurkan sekitar tujuh bulan yang lalu. Sehingga dalam hal ini pihak bank diharapkan untuk lebih meningkatkan sistem manajemen pada PDSB Mobile mengingat banyak keuntungan yang akan diperoleh.

\section{Matriks SWOT}

Berdasarkan matriks SWOT yang dijelaskan oleh Rangkuti (2016) maka dapat dilihat hasil analisis SWOT PT Bank Panin Dubai Syariah KCU Bandung sebagai berikut :

a. Berdasarkan Matriks Faktor Strategi Eksternal, Faktor opportunities menghasilkan skor nilai sebesar 1,84 dan faktor threats menghasilkan skor nilai sebesar 0,96 . Sehingga hasil dari faktor strategi eksternal yang berasal dari penjumlahan antar faktor opportunities dan threats adalah 2,80.

b. Berdasarkan Matriks Faktor Strategi Internal, dapat disimpulkan bahwa untuk faktor strengths menghasilkan skor nilai sebesar 2,11 dan faktor weakness menghasilkan skor nilai sebesar 1,07. Sehingga hasil dari faktor strategi internal yang berasal dari penjumlahan antar faktor strengths dan weaknesses adalah 3,18. 
c. Berdasarkan analisis Matriks SWOT, dapat disimpulkan bahwa perencanaan strategi yang diterapkan dan dimanfaatkan oleh PT Bank Panin Dubai Syariah dalam layanan jasa mobile banking adalah strategi SO atau dengan kata lain agresif dengan nilai sebesar 3,18. Dimana PT Bank Panin Dubai Syariah berusaha mengembangkan dan meningkatkan kualitas layanan jasa mobile banking dengan memanfaatkan kekuatan yang dimiliki dan peluang yang dihadapi. Sehingga PT Bank Panin Dubai Syariah KCU Bandung dapat memperoleh posisi yang menguntungkan.

\section{SIMPULAN}

Berdasarkan analisis SWOT di atas, maka dapat disimpulkan bahwa layanan mobile banking (PDSB Mobile) bisa menjadi salah satu produk unggulan PT Bank Panin Dubai Syariah agar bisa bersaing dengan bank lainnya, yang sudah lebih dahulu menggunakan produk sejenis. Selain itu, penggunaan mobile banking bisa memberi berbagai keuntungan terhadap bank, seperti meminimalisir biaya operasional, meningkatkan citra, sesuai dengan ajaran Islam, serta meningkatkan loyalitas dan kepercayaan nasabah. Adapun kelemahan layanan mobile bankin yang harus dibenahi adalah : Ketergantungan pada jaringan internet dan berjalan di atas service SMS dan SIM Tool, keamanan data nasabah, pemasaran produk kepada nasabah, serta mengoptimalkan minat dan daya tarik nasabah, serta meningkatkan target perusahaan.

Berdasarkan analisis SWOT, peluang pengembangan mobile banking di PT Bank Panin Dubai Syariah masih sangat besar, dilihat dari : Jumlah umat Islam di Indonesia sebagai calon pengguna mobile banking, pengembangan fitur, jaminan peraturan dan perizinan dari pemerintah, kemampuan customer service, dan relasi antara kantor pusat dan kantor cabang yang baik. Adapun ancaman yang harus dihadapi dalam pengembangan layanan jasa mobile banking PT Bank Panin Dubai Syariah yaitu : keterbatasan kemampuan bank untuk membaca persaingan pasar mobile banking, perkembangan segmentasi pasar mobile banking, tingkat penawaran dan kebutuhan nasabah, pengembangan pelayanan mobile banking oleh kantor pusat, dan pengembangan kemampuan manajerial dari pihak bank.

Adapun analisis strengths, weaknesses, opportunities, dan treaths pada layanan jasa mobile banking di PT Bank Panin Dubai Syariah yang diperoleh dari diagram 
cartesius menunjukan bahwa layanan mobile banking berada pada posisi kuadran I (satu) yaitu mendukung strategi agresif.

\section{DAFTAR PUSTAKA}

Abbas, S. K., Hassan, H. A., Asif, J., Junaid, H. M., \& Zainab, F. (2018). What are the key determinants of mobile banking Adoption in Pakistan. International Journal of Scientific \& Engineering Research, 841-848.

Abbas, S. K., Hassan, H. A., Iftikhar, S., \& Waris, A. (2018). Assimilation of TTF and UTAUT for Mobile Banking Usage. International Journal of Advanced Engineering, Management and Science (IJAEMS), 4.

Bungin \& Burhan. (2008). Analisa Data Penelitian Kualitatif. Jakarta: Prenada Media Group.

Cheng, D., Liu, G., \& Qian, C. (2008). On Determinants of User Acceptance of Internet Banking: A Theoretical Framework and Empirical Study. In Advance Management of Information for Globalized Enterprises. IEEE Symposium. https://doi.org/https://doi.org/10.1109/AMIGE.2008.ECP.20

Cheung, C. M., \& Lee, M. K. (2005). Consumer satisfaction with internet shopping: a research framework and propositions for future research. 7 th International Conference on Electronic Commerce. https://doi.org/https://doi.org/10.1 145/1089551.1089612

Chirani, I., \& Ghofrani, Y. R. (2010). Designing a model for explanation of the internet banking acceptance rate. In Information Management and Engineering (ICIME). The 2nd IEEE International Conference. https://doi.org/https://doi.org/1 0.1109/ICIME.2010.5478241

Darussalam, A. Z. and Malik, A. D. (2017). Konsep Perdagangan dalam Tafsir AlMishbah (Paradigma Filsafat Ekonomi Qur'ani Ulama Indonesia). ALTijarah.

Glaister, K. W., \& Falshaw, J. R. (1999). Strategic planning: Still going strong? Long Range Planning.

Habibi, Y. (2016). Refleksi setahun laku pandai. Republika. Retrieved from http://www.republika.co.id.

Hafiz, A. (2018). Analisis SWOT Layanan Mobile Banking Pada Bank Syariah Mandiri Kantor Cabang Pondok Indah. Jakarta.

Herawati, A., \& Listyawati, L. (2017). Faktor Penentu Keputusan Nasabah Muslim Dan Non Muslim Dalam Memilih Jasa Bank Syariah Di Kota Surabaya. Jurnal Ilmu Administrasi: Media Pengembangan Ilmu Dan Praktek Administrasi. https://doi.org/https://doi.org/10.31113/jia.v14i2.114

Hung, K. (2013). Understanding China's Hotel Industry: A SWOT Analysis Understanding China's Hotel Industry: A SWOT Analysis. Journal of China Tourism Research. https://doi.org/doi: 10.1080/19388160.2013.756771 
Ikatan Bankir Indonesia. (2014). Mengelola Kualitas Layanan Perbankan (Lembaga Sertifikasi Profesi Perbankan (LSPP). Jakarta: Gramedia Pustaka Utama.

Kadir, A. (2003). Pengenalan Sistem Informasi. Jakarta: Andi.

Karim, A. A. (2003). Islamic Banking: Fiqih and Financial Analysis. Jakarta: PT Raja Grafindo Persada.

Kim, Y. J., Chun, J. U., \& Song, J. (n.d.). Investigating the role of attitude in technology acceptance from an attitude strength perspective. International Journal of Information Management, 29(1). https://doi.org/https://doi.org/10.1016/j.ijinfomgt.2008.01.011

Kotler, P., dan G. A. (2008). Prinsip-prinsip pemasaran jilid 1. Jakarta: Penerbit Erlangga.

Moleong, L. J. (2005). Metodologi Penelitian Kualitatif. Bandung: Remaja Rosdakarya.

Mukhtar. (2013). Metode Penelitian Deskriftif Kualitatif. Jakarta: GP Press Group.

Ningrum, N. P. N. (2019). Analisis Strategi Bisnis pada Layanan Aplikasi Mobile Pegadaian Syariah Digital (PSD) Menggunakan SWOT Analysis.

Pavlou, F. (2001). Perceived Usefulnes, Perceived Ease of Use and User Acceptance of Information Technology. MIS Quarterly.

Rangkuti, F. (2016). Analisis SWOT: Teknik Membedah Kasus Bisnis Cara Perhitungan Bobot, Rating, dan OCAI. Jakarta: PT Gramedia Pustaka Utama.

Rema, Y.\& Setyohadi, D. B. (2016). Faktor-Faktor Yang Mempengaruhi Penerimaan Mobile Banking Studi Kasus: BRI Cabang Bajawa. Seminar Riset Teknologi Informasi (SRITI).

Ronny. (2017). Enam Kekuatan Layanan Jasa Internet Banking: Tinjauan Dari Persepsi Nasabah. Jurnal Organisasi Dan Manajemen.

Silver, L., Smith, A., Johnson, C., Taylor, K., Jiang, J., Anderson, M., \& Rainie, L. (2019). Mobile connectivity in emerging economies. Pew Research Center.

Sugiyono. (2018). Metode Penelitian Kuantitatif, Kualitatif, dan R\&D. Bandung: Alfabeta.

Tutuko, B., Hudaifah, A. and Zulfikar, D. (2017). Structuring Model for Corporate Productive Cash- Waqf in Indonesia (A Case Study of PT .Semen Indonesia). Journal of Islamic Finance, Special Issue.

Usman, R. (n.d.). Aspek Hukum Perbankan Syariah di Indonesia. Jakarta: Sinar Grafika.

Wibowo, Edy, dkk. (2005). Mengapa Memilih Bank Syariah? Bogor: Ghalia Indonesia cet.I. 